\title{
Psychic States Connection and Coping-Strategies of College Students in Different Life Situations
}

\author{
Velieva S.V. \\ I.Ya. Yakovlev State Pedagogical University \\ Cheboksary, Russia \\ stlena70@mail.ru
}

\author{
Yarabaeva N.Yu. \\ I.Ya. Yakovlev State Pedagogical University \\ Cheboksary, Russia \\ tatali22@mail.ru
}

\author{
Pavlova A.V. \\ I.Ya. Yakovlev State Pedagogical University \\ Cheboksary, Russia \\ anyav3571@mail.ru
}

\begin{abstract}
Nowadays it is obvious that a person in any situation should be able to preserve self-control, be ready to realize productive activity and effective communication. While studying at a college a student should outline life priorities and the system of values, master new life experience and the system of own psychic states self-regulation, master more effective mechanisms of behavior. Student's further behavior and the result of everyday difficult situations depends on his or her ability to operate own experience and resources. Statistical results of our research work show direct connection between psychic states and coping-strategy of behavior choice by a student depending on the specificity of situation (everyday, crisis, complicated). The more difficult and personally oriented problem is, the more rarely adaptive and productive strategies of behavior are used. If a personality often feels tranquility, optimism, activation and readiness to act, he or she has higher opportunity to develop and use relatively adaptive mental and behavioral coping-strategies and effective adaptive ways of self-control.
\end{abstract}

Keywords-psychic states; coping-strategies; connection; students; complicated situation; crisis; everyday

\section{INTRODUCTION}

During last decades the number of research works concerning psychic states in different situations and kinds of activity ([1],[2],[3],[4],[6]), their structural components ([5],[7],[8]), semantic spheres ([5]), mental representations of the state image ([4]) has considerably increased. It is conditioned by the fact that psychic states fulfill integrating role in psyche organization, provide connection between psychic processes and personal features, unity of physiological, physical and psychic functioning. The specificity of the dominating urgent psychic state among students conditions not only present, but also the future health state, unique character of subjective experience structuring, the character of a personality and relations with people around, strategies of self-control, effectiveness of socialpsychological adaptation to changing conditions of life, system of activity and behavior regulation. In this connection one of the main objectives of any educational establishment should be favorable conditions provision for students' personality development, their health state protection and improvement.

\section{LITERATURE REVIEW}

Not taking into account the psychological school to which this or that scientist belongs, all they underline that a person is the most unique of all known systems, which has difficult characteristics. Any system perception provides studying its components interconnection [9]. An integral approach to psychic states study as a special category of psychic phenomena demands system analysis and synthesis, content and structure, system forming factors, behavior regulations and dynamics explanation.

In this aspect studying the influence of the definite copingstrategy on this or that component of psychic state is important for interconnections revelation between the separate sides of system structure and psyche development [1], [9]. The facts, received during such kind of research works, would help to explain psychological mechanisms and subjectively effective coping-strategies creation and mastering, on the one hand, and on the other hand, reveal their influence on physiological and psychic processes, the sphere of experience and behavior. A.O. Prokhorov [5] defines psychic states in the dynamics of psychic activity as an integral steady syndrome, revealed together with behavior and experience in time continuum. Determinants of psychic states are subjectively significant for a subject life situations (environment factor), sense-forming, interactive and disposition factors in connection with urgent personal qualities and characteristics.

N.D.Levitov [10] includes physiological, psychological and social parts into the structure of states. A.O. Prokhorov [5] considers the component content of psychic states in an integral unity of structural, information, dynamic, energetic components of all psyche.

V.A. Ganzen, V.N. Yurchenko [11] define substructures in the composition of psychic states. The first substructure (hierarchic) includes physiological, psycho-physiological, 
psychological, social-psychological levels. The second substructure (coordinating) includes subjective (personified experiences) and objective (fixed) sides. The third substructure (system) includes general, specific and individual attributes of psychic states demonstration.

It is obvious that it is reasonable to study personality in unity with qualities and features, which are developed and demonstrated in activity. For students one of significant kinds of activity is educational activity.

The research works show close connection between psychic states and activity (A.B. Leonova[12], A.O. Prokhorov[5]), (O.F. Gefele[13], S.A. Raschetina[14], B.Ya. Sharifullina[15]). For this research work the following notions are important: everyday, crisis and complicated (situation of uncertainty) situations of life.

Everyday situation is considered as the segment, unit of life activity measurement, an open system of external and internal factors, which condition activity of a subject. In everyday situation a person exposes oneself naturally in common perception and environment interpretation. In everyday situations subjective attitude to life is revealed, steady cognitive and behavioral styles are formed, personal experience is structured.

Unexpected involvement into unknown situation, which places demands exceeding subject's resources (physiological, social-psychological, behavioral), unexpected change and life balance violation can characterize crisis situations.

Examination is a real complicated situation of uncertainty for a student (G.M. Ldokova, A.N. Panfilov[6], B.Ya. Sharifullin[15]). Examination defines not only present (the level of mastering the discipline), but also the past (realized and gradual character of mastering competencies, current control rating, involvement into educational process) and the future (scholarship, intermediate control results) [16,17].

The checking test as a special way of a student and a teacher interaction includes three subjective processes: attitude, activity and communication (S.A. Raschetina [14]). Psychic states are developed in case of communication subjects' personal qualities, sense and subjective processes of situation interaction. Intensive training, time limits, uncertainty in the results of the exam lead to nervous system over-tension (G.M. Ldokova [6]), stress character demonstration and negative changes in mood.

In each mentioned above situations we see the deficiency of basic person's needs satisfaction, adaptive resources and usual forms of behavior disorder under the influence of external (objective) and internal (subjective) factors. It is easier to adapt to changed life situation, recover inner balance, preserve adaptability, communication effectiveness and activity effectiveness, get rid of negative psychic states by means of these or that coping-strategies.

"Coping" includes affective, mental and verbal-behavioral ways of possible in the future and present internal and external factors situations, dispositional factors of a personality transformation in order to achieve psychological balance of a subject and environment.
Theoretical analysis showed that the influence study of behavioral strategies on psychic states transformation among college students in different life situations (everyday, crisis, complicated) would help to predict the effectiveness and expediency of this or that coping development. This is the main aim of our research work.

\section{RESEARCH METHODOLOGY}

16-17 year-old students of Economic-Technological College took part in the research $(n=75)$. In order to study the strategies of behavior (distancing and self-control, confrontation and searching for social support, planning and positive reconsideration, responsibility and avoidance) copingtest by R. Lazarus was used. 40 different structural parameters of psychic states (physiological and psychic processes, sphere of experience and behavior) were measured with the help of A.O. Prokhorov questioner survey "Psychic states relief". Each characteristic of psychic states has 11 levels of intensity and three degrees of expressiveness: high (8-11 points), the average (4-7points) and low (0-3 points). The type of psychic states revelation in each situation was realized with the help of SUPOS-8 methodology (O.Mikshik), in adaptation of V.A. Kulganov.

The procedure of the research was presented as a gradual text of the questioner surveys presentation. It was offered to visualize oneself in everyday, crisis and complicated situation (during the examination), define typical psychic states, estimate changes in their structure, personal strategies of behavior in different life situations.

Statistical data handling was held with the help of Student t-test. The indices of close and very close connection in terms $\mathrm{p} \leq 0,01 ; \mathrm{t}_{\mathrm{emp}}=4.4-5.3$, the level of confidence coefficient $95 \%$ were taken into consideration. The parameters of non-linear regression were taken into consideration within 2.14 (in case $\mathrm{p} \leq 0,05)-2.98$ (in case $\mathrm{p} \leq 0,01$ ).

\section{RESUlTS}

Respondents' psychic states indices in everyday situations correspond with a high level of their mobilizing components. Tranquility $(21,22)$, optimism and activation, strength and energy $(18,52)$, readiness to act $(12,95)$ are typical for students. Some students showed impulsive reactivity $(5,6)$, oppression $(4,58)$, depression and exhaustion $(4,56)$, anxiety $(3,87)$, uneasiness $(3,23)$.

These states are demonstrated through psychic processes activation (clearness of perception $(9,96)$, memory $(9,92)$, imagination $(9,88)$ ). Least of all into everyday situations are involved the parameters of feeling $(7,48)$. Among physiological processes we define sufficient coordination of movements $(9,75)$, slightly increased state of muscle tone and motor activity $(9,12$ each). Sweating $(8,29)$, temperature changes $(8,19)$ and skin integuments $(7,51)$ correspond with the average values. Among the parameters of experience sphere prevail the following: optimism $(9,81)$, gaiety $(9,6)$, activity $(9,52)$. Other characteristics of experience sphere have the average values. Most respondents consider their behavior adequate to a situation $(10,12)$ and controlled $(10,08)$. 
In everyday life situations respondents more often use positive reconsideration $(42,67 \%)$, self-control and planning (41,33\% each). Relatively adaptive mental and behavioral coping-strategies and affective adaptive ways of control are used in the average values.

Demobilizing indices of psychic states in crisis situations increase twice or more, and mobilizing ones decrease. Together with psychic tranquility $(12,6)$, activation and energy $(12,52)$, readiness to act $(10,62)$, we have considerable increase of tension $(7,95)$ and anxiety $(7,76)$, depression and emptyness $(6,95)$, impulse reactivity $(6,25)$ and oppression $(4,58)$. In crisis situation the sphere of experience $(5,89)$, psychic $(7,07)$ and physiological $(7,11)$ processes and effectiveness of behavior $(7,44)$ suffer. Respondents mention sadness $(4,93)$, dreariness $(4,99)$, sorrow $(5,09)$, passivity $(6,31)$, despair $(6,43)$; tension increase $(5,89)$, bad mood $(5,95)$, sense of restrain $(6,02)$, heart heaviness, $(5,71)$. Psychic processes lose their effectiveness, especially emotions $(5,84)$, feelings $(6,08)$, attention $(6,75)$, will power $(7,04)$. Other processes preserve low border of normative value. Some sides of physiological processes are influenced greatly. Respondents underline their own paleness $(6,76)$, extremities cooling $(6,84)$, intensive sweating $(6,81)$, muscle tension, hands tremor $(6,89)$ and respiration difficulty $(7,12)$, dry mouth, $(7,08)$, nausea $(7,21)$. Behavior becomes more passive $(6,55)$, rigid $(6,59)$, impulsive $(6,87)$, inconsistent $(6,95)$, constrained $(7,16)$.

In crisis situation respondents prefer searching for social support $(70,67 \%)$, distancing $(62,67 \%)$, avoidance $(56 \%)$, confrontational coping $(54,67 \%)$. Lesser they use self-control $(37,33 \%)$, responsibility taking $(45,33 \%)$, positive reconsideration $(41,33 \%)$.

The states during the examination are characterized by sufficient strength, energy preservation $(13,79)$, tranquility $(13,1)$, desire to act $(10,66)$. In comparison with everyday situation mobilizing factors also decrease, demobilizing factors increase, though less than in crisis situations. In uncertain complicated conditions we register dispiritedness $(7,88)$, tension and anxiety $(7,58)$, exhaustion $(6,79)$, suspense $(6,06)$. In comparison with everyday situation there is all sides of psychic states worsening during the examination: sphere of experience $(6,91)$, physiological $(7,78)$ and psychic $(7,88)$ processes, effectiveness of behavior $(8,00)$. In comparison with crisis situation suffers the following: sphere of experience, which is demonstrated in sense of melancholy, $(6,24)$, sadness $(6,32)$, sorrow $(6,39)$, passivity increase $(7,67)$, apathy $(8,00)$, sense of tension $(6,11)$, heaviness $(6,83)$, constrain $(7,05)$. During the examination excretory system $(7,07)$, respiratory organs $(7,87)$, digestive tract $(7,41)$, cardiovascular system $(7,95)$ experience negative influence. Psychic processes effectiveness during the exam also decreases: fears and despair appear $(6,69)$, susceptibility to external influences becomes worse $(7,55)$ it is difficult to understand the essence of things $(7,97)$, uncertainty and laziness appear (7,65), distractibility increases (7,71). In comparison with crisis situation indices of thinking $(8,21)$, speech (8,57), memory $(8,6)$ increase. Behavioral characteristics of psychic states in an uncertain situation are similar to the same demonstrations in crisis situation. The difference was in greater reasoning $(8,19)$, activity $(7,91)$, consistency $(7,77)$, regularity $(7,29)$, complete readiness for action $(7,24)$, steadiness $(8,35)$ and confidence $(8,75)$.During the examinations more often students used social support (72\%), distancing (64\%), avoidance $(50,67 \%)$, confrontational coping $(56 \%)$. Some respondents had high self-control $(45,33 \%)$, decision planning $(38,67 \%)$.

\section{DISCUSSION}

College students in everyday situations are characterized by psychic states. They are considerably favorable for personal development, educational activity and effective behavior realization. They are able to use adaptive copingstrategies. It is stated that for respondents, who show tranquility, optimism, activity, power and energy, readiness to act, it is typical to use relatively adaptive mental and behavioral coping-strategies and affective adaptive ways of self-control. They stay available for students in crisis and complicated situations.

Crisis and complicated situations most of all ruin the sphere of experience. In crisis situations also suffer psychic processes, in complicated - physiological processes. It can be connected with time limit, subjective perception violation and restriction under the influence of stresses in situations, which demand new adaptive mechanisms, personal new formations. In case of examination, and especially in crisis situations the mastered earlier adaptive and steady coping-strategies can be not activated. Statistical results show the connection of psychic states and coping-strategy choice by students depending on specificity of situation (everyday, crisis, complicated). The more difficult and personally oriented problem is, the more rarely adaptive and productive strategies of behavior are used. The aim of teachers and college psychologists is to provide conditions for readiness formation among students to use adequate, steady and effective strategies of behavior in different life situations.

\section{CONCLUSION}

More harmoniously a person's psyche functions in everyday life situations. It is proved by indices correspondence of psychic states substructures: psychic $\left(\mathrm{t}_{\mathrm{emp}}=4.4\right)$ and physiological $\left(\mathrm{t}_{\mathrm{emp}}=4.6\right)$ processes, experiences $\left(\mathrm{t}_{\mathrm{emp}}=4.5\right)$ and behavior $\left(\mathrm{t}_{\mathrm{emp}}=4.4\right)$.

In crisis situation there is more considerable all substructures repression, at the same time, more negative experiences prevail $\left(\mathrm{t}_{\mathrm{emp}}=5.3\right)$, psychic and physiological processes $\left(\mathrm{t}_{\mathrm{emp}}=5\right.$ each) and behavior $\left(\mathrm{t}_{\mathrm{emp}}=4.9\right)$ functioning worsening.

Non-adaptive strategies of behavior choice, responsibility abandoning in crisis situations conditions low effectiveness of behavior $(r=0,7$ in case $p \leq 0,01)$, increases discomfort in the sphere of experiences $(r=0,28$ in case $\mathrm{p} \leq 0,01)$, creates over-tension in psychic $(\mathrm{r}=0,6$ in case $\mathrm{p} \leq 0,01)$ and physiological processes $(r=0,46$ in case $p \leq 0,01)$. For this group of respondents psychic states of stress, anxiety, depression and impulse reactivity are typical.

In the situation of uncertainty (examination) there indices increase of all sides of psychic states. In comparison with 
[5] A.O. Prokhorov "Mental representations of psychic states: phenomenological and experimental characteristics", Experimental psychology. 2016, vol. 9, 2, pp. 23-37.

everyday situation there is considerable indices increase of experiences $\left(t_{\mathrm{emp}}=5\right)$. In psychic and physiological processes indices $\left(\mathrm{t}_{\mathrm{emp}}=4.8\right.$ each $)$, behavior $\left(\mathrm{t}_{\mathrm{emp}}=4.7\right)$ there is tendency for mobilization.

The higher negative states indices are, more often students use searching for social support $(r=0,66$ in case $\mathrm{p} \leq 0,01)$, problems avoidance $(\mathrm{r}=0,59$ in case $\mathrm{p} \leq 0,01)$, distancing $(\mathrm{r}=0,48$ in case $\mathrm{p} \leq 0,01)$, confrontational coping $(r=0,38$ in case $\mathrm{p} \leq 0,01)$ in crisis situation.

\section{References}

[1] Nikolaev E., S. Petunova, S. Velieva, O. Pinyaeva "Bulling and Victim Behavior in Rural Secondary School among Students: Incidence, Manifestations, Interrelations", The European Proceedings of Social \&BehaviouralScincesEpSBS:ECCE. 2018, 17-20 May, vol. XLIII, 70, pp. 528-534.

[2] N.Maksimova, A. Zakharova, N. Grigorieva, E.Nikolaev, E. Lazareva, E. Baranova,S. Velieva "Body Modification and Self-Destructive Behavior in Adolescents: Psychological Manifestations", Advances in Social Science, Education and Humanities Research. InternationalConferenceonPedagogy, CommunicationandSociology. ICPCS. 2019, vol. 315, pp. 417-420.

[3] L.G. Dikaya, "New system of psychic regulation formation in extreme conditions of activity", Organizational psychology and psychology of labor. 2019, vol. 4, 1, pp. 199-221.

[4] A.O. Prokhorov, M.G. Yusupov "Mental regulation of cognitive states in intellectual activity of teen-agers", Siberian Psychological Magazine. 2018, 70, pp. 6-16.
[6] G.M. Ldokova, A.N. Panfilov "Psychological states of students in complicated conditions of educational activity", Concept. 2013, 1, pp. 111.

[7] E.P. Ilin "Emotions and senses", Saint-Petersburg: Piter. 2010, 784.

[8] T.A. Klimontova, Yu.V. Chepurko "Characteristics of psychic states in proceedings, series: Psychology. 2016, vol. 18, pp. 32-37.

[9] B.F. Lomov "Methodological and theoretical problems of psychology", Moscow: Science. 1984, 444

[10] N.D. Levitov “About psychic states of a person”, Moscow. 1964, 344.

[11] V.A. Ganzen, V.N. Yurchenko "System character of a person's psychic states", LGU Bulletin. 1991, 1, pp. 47-55.

[12] A.B. Leonova, A.S. Kuznetsova "Structural-integrative approach to functional states analysis: history of creation and prospects of development", Moscow University bulletin, Series 14: Psychology. 2019, 1, pp. 13-33.

[13] O.F. Gefele "Extreme situation influence on personality's psychic state change", Symbol of science. 2015, 10-2, pp. 240-242.

[14] S.A. Raschetina "Situation as the object of research in the sphere of social pedagogics", Siberian Pedagogical magazine. 2013, 2, pp. 10-16.

[15] B.Yu. Sharifullin "Examination as a difficult communicative situation of reality", Ecology of language and communicative practice. 2015, 2(5), pp. 313-330.

[16] Aleksandr S. Kuznetsov, Evgeniya N. Usmanova, Oksana V. Kolomytseva. Athletes' psychological-physiological indices study in different specializations at the stages of sports career crises overcoming. Russian Journal of Physical Education and Sport. 2019, 14(2), pp. 81-87. DOI: $10.14526 / 2070-4798-2019-14-2-89-96$

[17] Alexsandr S. Kuznetsov. Russian Professor's meeting. Russian Journal of Physical Education and Sport. 2019, 14(1), pp. 17-22. DOI: 10.14526/2070-4798-2019-14-1-18-24 terms of different level of personality vitality", Irkutsk State University 